\title{
Long-term availability of generation capacity in the market- driven electric power industry
}

\author{
Oleg V. Khamisov ${ }^{1}$, Sergei $V$. Podkovalnikov, ${ }^{1, *}$, and Konstantin A. Semenov ${ }^{1}$ \\ ${ }^{1}$ Melentiev Energy Systems Institute of the Siberian Branch of the Russian Academy of Sciences (ESI SB RAS), 664033 Lermontov str., \\ 130, Irkutsk, Russia
}

\begin{abstract}
The study investigates the issues of long-term availability of generation capacity in a market environment. The expansion of the electric power industry is analyzed, taking into account its one-product and two-product structural organization as well as its splitting into separate generation companies pursuing their own economic interests in an imperfect market. A case study is provided.
\end{abstract}

\section{Introduction}

With the introduction of market relations into the electric power industry of Russia, a number of actors have been established that are in charge of the justification of its expansion and the decision-making related thereto. Power companies now operate as if acting primarily in their own economic self-interests, when justifying and making decisions on the expansion of production capacity (though they are constrained by various reference documents, regulations, and rules). Pursuing these interests, especially so under imperfect competition that arises in the power market (PM), does not necessarily yield a system-wide optimal state. Therefore, research and assessment of the effectiveness of the expansion of power systems (PS) under their splitting into individual power companies that operate in an environment of imperfect competition are required to supplement the conventional optimization-driven technical and economic studies employed to justify the expansion of the electric power industry.

To do research, given the unbundling of power systems into separate generation companies (GenCo), and taking into account their interests, we need dedicated mathematical equilibrium models that would enable us to optimize the objective functions of the effectiveness of these companies. Such models were developed abroad [1-4]. In Russia, similar models were developed by the authors of this paper for one-product and two-product types of organization of the power market. They are presented in [5-7] and are not covered here. Unlike the research published abroad, they take into account the technical properties of the power system in sufficient detail.

\section{Input data and background}

We studied the Interconnected Power System (IPS) of the Center of the European section of the Unified Power
System (UPS) of Russia. In this interconnected power system, transmission networks are highly developed, which serves as a certain rationale behind treating it as concentrated and, hence, representing them for the purposes of modelled calculations as a single node. The requirement of a single-node representation of the power system follows from the fact that the equilibrium models, as it stands now, do not allow finding solutions that apply to entire networks.

The above IPS is made up of a wide range of generation companies of both federal (wholesale generation companies: WGC-1,3,4,5,6, RusHydro, Rosenergoatom, INTER RAO UES) and regional (territorial generation companies: TGK-2,3,4,6, MPC [Moscow Power Company]) significance.

The expansion of various types of power plants, as well as the demand for electricity, are in compliance with a number of documents forecasting the expansion of the electric power industry of Russia, including the draft document of the Energy Strategy of Russia to 2035, the up-to-date adjustments of the Scenario Conditions for the Electric Power Industry Expansion to 2030, the Master Plan and the Expansion Program of the UPS of Russia for years 2018 to 2024, and other publications [810].

According to the above documents, the power demand and the annual maximum load for the IPS under consideration were set as equal to $422 \mathrm{TWh} /$ year and 69 GW for the assumed target year of 2030.

Table 1 shows the economic indicators of power plants, including investments, fixed operating and fuel costs [10-14]. The number of hours of utilizing the power of hydroelectric power plants (HPP) in each season was assumed to be equal to: 631 (winter), 432 (spring), 761 (summer) and 652 (autumn) hours. The daily number of hours of utilizing the power of the pumped storage power plants (PSPP) was set to 5 . The number of equivalent operating days and holydays in each season was assumed as: 64 and 26 (winter), 64 and

\footnotetext{
* Corresponding author: spodkovalnikov@isem.irk.ru
} 
27 (spring), 65 and 25 (summer), and 64 and 26 (autumn) days respectively.

The electricity demand function was obtained relying on the method presented in [5]. To this end, the longterm elasticity of demand for electricity was used, which is uncertain. Various sources present different estimates of the long-term elasticity of demand for electricity $[11,12]$. Based on the analysis of these sources, this elasticity was assumed to be taking the following values: $-0,5 ;-0,7 ;-0,9$. The average of these values is considered as the most likely one.

Table 1. Power plants economic indicators

\begin{tabular}{|l|c|c|c|c|c|}
\hline \multicolumn{1}{|c|}{ Indicators } & PSPP & $\begin{array}{c}\text { Coal } \\
\text { Thermal }\end{array}$ & $\begin{array}{c}\text { Gas } \\
\text { Thermal }\end{array}$ & Nuclear & $\begin{array}{c}\text { Coge- } \\
\text { neration }\end{array}$ \\
\hline $\begin{array}{l}\text { Capital } \\
\text { investment, } \\
\text { USD/kW }\end{array}$ & 840 & 1400 & 750 & 2250 & 1050 \\
\hline $\begin{array}{l}\text { Fixed operating } \\
\text { costs, \%/capital } \\
\text { investment }\end{array}$ & 3 & 4 & 5 & 4 & 3 \\
\hline $\begin{array}{l}\text { Fuel costs, } \\
\text { cent/kWh }\end{array}$ & - & $2.2-3.2$ & $3.5-4.8$ & 0.7 & $3.5-4.6$ \\
\hline
\end{tabular}

The long-term elasticity of demand for capacity (when constructing the function of demand for capacity in the PS expansion model while taking into account a two-product organizational structure of electric power industry) was assumed to be similar to the above indicated long-term elasticity of demand for electricity.

\section{Electric power industry expansion scenarios}

Two groups of calculation scenarios were formed for the one-product and two-product electric power industry structures. The one-product organizational structure, although it does not fully capture the actual organization of the modern electric power industry of Russia, is required, first of all, as a baseline to assess the twoproduct structure against.

Under the first scenario of the first group $\left(\mathrm{S}_{\mathrm{O}} 1\right.$; subscript "o" denotes the one-product organizational structure), the situation of perfect competition is considered when GenCo's, acting in their self-interests, actually maximize the system-wide effectiveness. This scenario serves as a "baseline" to assess the subsequent scenarios.

Under the second scenario $\left(\mathrm{S}_{\mathrm{O}} 2\right)$, the organizational unbundling of the electric power industry split into separate companies is supposed to maximize the objective functions of the performance of GenCo's and takes into account imperfect competition. This captures the trend of horizontal integration, that is GenCo's mergers. As a result, with the advent of larger GenCo's in the Center IPS, their number is declining, thus serving as prerequisites for their strategic behavior.

Under the third scenario $\left(\mathrm{S}_{\mathrm{O}} 3\right)$, the PM entry of a new GenCo in the long-term period is investigated, as well as its effect on the main market parameters (equilibrium price, electricity supply, and new capacity additions).

Under the fourth scenario $\left(\mathrm{S}_{\mathrm{O}} 4\right)$, it is assumed that the long-term expansion of Rosenergoatom, as a stateowned company, will progress in accordance with established plans. To this end, the NPP capacity in the model is not optimized, but is set (fixed) at a certain planned level (for the assumed target year).

Under the first scenario of the second group $\left(\mathrm{S}_{\mathrm{T}} 1\right.$; subscript " $\mathrm{T}$ " indicates the two-product organizational structure), the situation of perfect competition on the two-product electricity and capacity market is considered, when GenCo's actually maximize social welfare. This scenario also acts as the baseline (for comparison) for the next scenario.

Under the second scenario of this group $\left(\mathrm{S}_{\mathrm{T}} 2\right)$, we assume organizational unbundling of the electric power industry split into separate companies, maximization of GenCo's objective functions of effectiveness, and the presence of imperfect competition.

\section{Electric power industry expansion in a one-product organizational structure}

The key findings of a study of the expansion of a one-product organizational structure of the electric power industry with one-product (electricity) trading are shown in Figures 1-4 and Table 2 for the average value of long-term elasticity of demand for electricity $(-0,7)$.

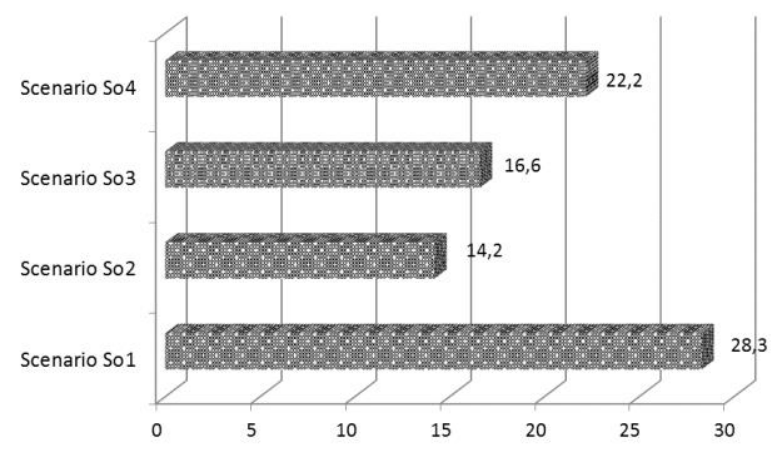

Fig. 1. New generation capacity additions under the oneproduct organizational structure of the electric power industry, Center IPS, 2030, GW.

As can be seen from Figure 1, under organizational unbundling, independent maximization of GenCo's objective functions, and imperfect competition in the absence of the necessary regulatory influences, new generation capacity additions diminish. Additions are kept to a minimum in the case of GenCo merging $\left(\mathrm{S}_{\mathrm{O}} 2\right)$, accounting for only half of the additions that take place under perfect competition. This is due to the fact that the GenCo merger paves the way for the dominance of aggregated companies, hence enhancing their market power. A new competitor that is established on the basis of new power plants (scenario $\mathrm{S}_{\mathrm{O}} 3$ ), expands its capacity to the maximum. This leads to an increase in total additions if compared to the $\mathrm{S}_{\mathrm{O}} 2$ scenario, under which this capacity is only partially added. Under the $\mathrm{S}_{0} 4$ 
scenario, the maximum additions of generation capacity (over all "market-driven" scenarios) is provided, although they are still somewhat lower than under the $\mathrm{S}_{\mathrm{O}} 1$ scenario of perfect competition. This result is due to establishing the requirements on nuclear power plants expansion.

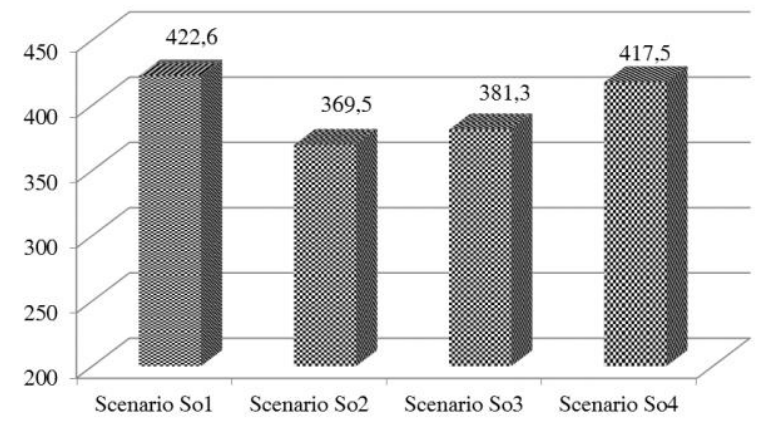

Fig. 2. Electricity supply for a one-product organizational structure of the electric power industry, Center IPS, 2030, $\mathrm{TWh} /$ year.

The above strategic GenCo behavior leads to corresponding electricity undersupply by generation companies. Under the $\mathrm{S}_{\mathrm{O}} 2$ and $\mathrm{S}_{\mathrm{O}} 3$ scenarios, the supply is significantly lower than that under perfect competition (see Figure 2). Under the So4 scenario, the electricity supply is higher if compared to the above two scenarios, although it is still lower than under the reference case. As a result, consumers are forced to cut down their electricity consumption in the long run, moving away from the amount that is optimal social welfare-wise and suffering a corresponding economic loss. This loss is due to an increase in equilibrium electricity prices. As follows from Figure 3, the average annual equilibrium electricity prices for the $\mathrm{S}_{\mathrm{O}} 2$ and $\mathrm{S}_{\mathrm{O}} 3$ scenarios increase by $14-18 \%$ if compared to the $\mathrm{S}_{\mathrm{O}} 1$ scenario. It should be noted that under the $\mathrm{S}_{\mathrm{O}} 3$ scenario, the price gets slightly lower relative to the $\mathrm{S}_{\mathrm{O}} 2$ scenario. This is explained by the entry of a new power market participant under the $\mathrm{S}_{\mathrm{O}} 3$ scenario, which somewhat limits the market power of other participants and their negative impact on the level of equilibrium prices. Under the $\mathrm{S}_{0} 4$ scenario, the increase in the equilibrium price is kept to a minimum.

Figure 3 also shows the economic losses of consumers from overstatement of equilibrium prices. As can be seen, these losses are quite large, and in the case of Center IPS reach 4.6-5.5 billion dollar/year by the year 2030. It should be noted, however, that consumer losses under the $\mathrm{S}_{\mathrm{O}} 3$ scenario are almost 1 billion dollars lower than those under the $\mathrm{S}_{\mathrm{O}} 2$ scenario. As explained above, this is due to the emergence of a new participant of the power market under the $\mathrm{S}_{\mathrm{O}} 3$ scenario. Losses of consumers are kept to a minimum under the $\mathrm{S}_{0} 4$ scenario, when NPP capacity additions are regulated/fixed, it, in turn, increases electricity supply by this type of power plants and hence decreases the equilibrium price.

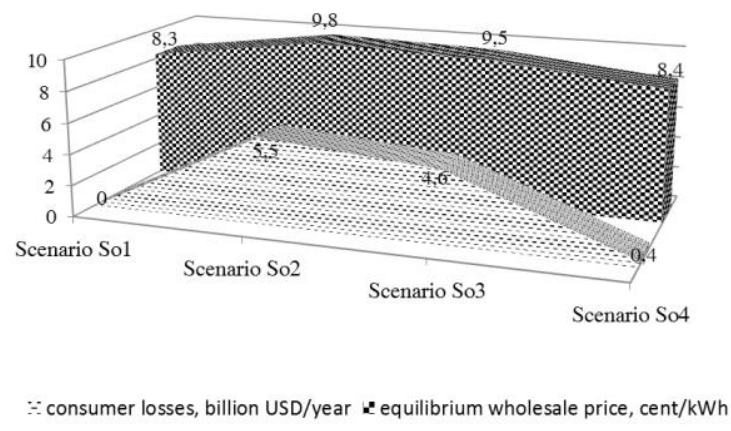

Fig. 3. Equilibrium prices and losses of electricity consumers in a one-product organizational structure of the electric power industry, Center IPS, 2030.

Under the organizational splitting of the electric power industry into GenCo's and independent optimization of their objective functions, not only the generation capacity additions and electricity supply are reduced, but also the mix of electricity generation by various types of power plants changes significantly in some cases. At the same time, the effectiveness of electricity production as a whole decreases.

It should be emphasized that under all considered scenarios and all conditions, both hourly power balances and annual electricity balances were checked and met, alongside ensuring the necessary operating modes of various types of power plants for given daily, weekly, and annual power consumption modes.

\section{Electric power industry expansion in a two-product organizational structure}

With the introduction of the capacity trading mechanism, along with electricity trading, the new generation capacity additions increase significantly even under imperfect competition (see Figure 4). As can be seen from Figure 4, under imperfect competition, new capacity additions are a mere $1 \mathrm{GW}$ short of those under perfect competition. At the same time, for a one-product organization of the electricity industry, capacity additions are 6 to $14 \mathrm{GW}$ lower under imperfect competition, depending on the conditions under consideration (see Figure 1).

Same time, the aggregate equilibrium prices for a two-product organizational structure are higher than those for a one-product one (see Figures 3 and 4). This is due to the fact that in the one-good (electricity) market, the equilibrium price is formed based on the total cost (including investment) of the marginal facility. When dividing the power market into two markets (those of electricity and capacity), each of them has the price formed based on different marginal facilities.

Under scenario $\mathrm{S}_{\mathrm{T}} 2$, given imperfect competition, the price increases relative to that under perfect competition (scenario $\mathrm{S}_{\mathrm{T}} 1$ ). At the same time, if compared to the conditions of imperfect competition and a one-product electric power industry structure (scenarios $\mathrm{S}_{\mathrm{O}} 2, \mathrm{~S}_{\mathrm{O}} 3$, $\mathrm{S}_{\mathrm{O}} 4$ ), under scenario $\mathrm{S}_{\mathrm{T}} 2$, as was already noted, more new capacity additions are introduced into the power 
system, thereby increasing their long-term supply availability.

Although, as mentioned above, new generation capacity additions under imperfect competition in the case of a two-product organization of the electric power industry decrease slightly if compared to that under perfect competition, as the calculations show, the mix of these additions noticeably altered. Under scenario $\mathrm{S}_{\mathrm{T}} 2$, the share of additions of effective nuclear power plants is significantly reduced, which leads to deterioration of the mix of electricity generation under this scenario.

The mix of electricity generation under perfect competition for scenario $\mathrm{S}_{\mathrm{T}} 1$ despite closely resembling the generation mix for scenario $\mathrm{S}_{\mathrm{O}} 1$ (one-product structural organization of the electric power industry), is still somewhat different from it. This is due to the fact that there is a transition from optimization of a unified one-product electric power structure to what is actually the optimization of two different structures independently (one of which is for trading electricity, while the other one is for capacity). In this case, a certain loss of effectiveness occurs, as evidenced by the growth of equilibrium aggregate prices under scenario $S_{T} 1$ as compared to scenario $\mathrm{S}_{\mathrm{O}} 1$.

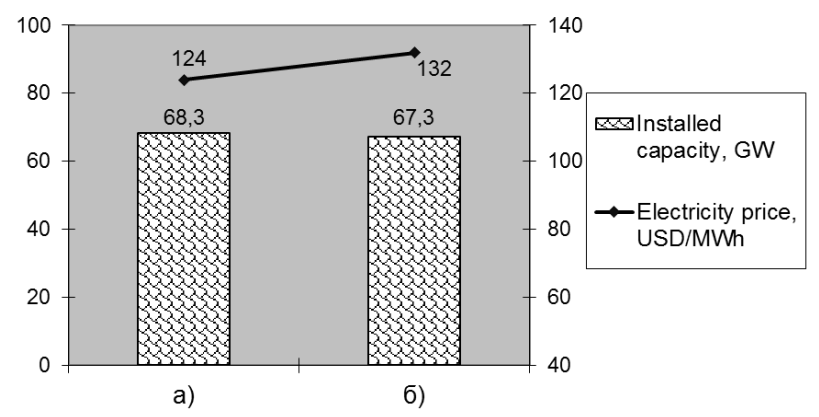

Fig. 4. Installed capacity and aggregate equilibrium price of electricity, Centre IPS, 2030: a) scenario $\mathrm{S}_{\mathrm{T}} 1$ of a two-product structural organization of the electric power industry under perfect competition; b) scenario $\mathrm{S}_{\mathrm{T}} 2$ of a two-product structural organization of the electric power industry under imperfect competition.

In general, it should be noted that for a two-product PM under imperfect competition, the mix of electricity generation by type of power plants differs from the generation mix under perfect competition to a lesser extent than is the case for a one-product market.

\section{Conclusion}

1. Given a one-product structure of the electric power industry and the absence of the necessary regulatory influences, new generation capacity additions decrease (if compared to the conditions of maximizing the system-wide effectiveness of the electric power industry). At the same time, the additions are kept to a minimum in the case of GenCo's merging, accounting for only half of the additions that take place under perfect competition. This is due to the strategic behavior of the dominant consolidated companies. This decrease in additions leads to corresponding electricity undersupply. As a result, under imperfect competition, equilibrium prices increase by $14-18 \%$ if compared to those under perfect competition. Losses of consumers in the Center IPS due to such overpricing can reach 4.6-5.5 billion dollar/year by the year 2030 .

2. Within the two-product electric power industry structure, with the introduction of the capacity market mechanism, the new generation capacity additions significantly increase if compared to the one-product structure even under imperfect competition. Within the framework of this organizational structure, under imperfect competition, capacity additions are a mere $1 \mathrm{GW}$ short of those under perfect competition. Accordingly, the long-term availability of generation capacity increases. However, this triggers an increase in the equilibrium price.

3. The scope of the studies traditionally carried out in Russia to justify the expansion of electric power industry should be extended to address the issue of the organizational unbundling of the electric power industry and self-interests of power companies in order to identify and adjust their behaviour in the long run.

The research was carried out under State Assignment, Project 17.4.2 (reg. no. AAAA-A17-117030310438-1) of the Fundamental Research of Siberian Branch of the Russian Academy of Sciences.

\section{References}

1. J. Bushnell, J. Ishii, CSEM, 164 (2007)

2. M. Ventosa, A. Baillo, A. Ramos, The Energy J. 33, 7 (2005)

3. F. Murphy, Y. Smeers, Oper. Res. 53, 4 (2005)

4. A.V. Borisenko, S.E. Saukh, Proceedings of Modeling-2010, IPME, 185-194 (2010) (In Russian)

5. S.V. Podkovalnikov, O.V. Khamisov, Izvestija RAN. Energetika, 2, 66-86 (2011) (In Russian)

6. O.V.Khamisov, S.V.Podkovalnikov, Proceedings of 2011 IEEE PowerTech, Trondheim University, 506512 (2011)

7. S.V. Podkovalnikov, K.A. Semenov, O.V. Khamisov, Izvestija RAN. Energetika, 4, 3-14 (2014) (In Russian)

8. The draft document of the Energy Strategy of Russia to 2035, Electronic publication, (2017). https://minenergo.gov.ru/system/downloadpdf/1920/69055 (In Russian)

9. Scenario conditions for the development of the electric power industry to 2030, Electronic publication, (2011). $\quad$ http://www.eapbe.ru/5years/sc 2012 2030/SC 2012-2030new.php.html (In Russian)

10. Order of the Energy Ministry of Russia dated 02.28.18 No. 121, Electronic publication, (2018). https://minenergo.gov.ru/view-pdf/11323/82788 (In Russian) 
11. L. Gilotte, D. Finon, CIRED, Online reference, (2006). www.centre-cired.fr/IMG/pdf/9 GilotteFinon inv pouvoir marche. pdf.pdf

12. The power to choose. Demand response in liberalized electricity markets. IEA, 156 (2003)

13. E.P. Volkov, V.A. Barinov, A.S. Manevich, Methodology of substantiation and prospects for the development of the electric power industry of Russia (Energoatomizdat, Moscow, 2010) (In Russian)

14. N.I. Voropai, S.V. Podkovalnikov, V.V. Trufanov, Substantiation of the development of power systems: Methodology, models, methods, and their application (Nauka, Novosibirsk, 2015) (In Russian) 